\title{
Development and Pilot of a Low-Literacy Diabetes Education Book Using Social Marketing Techniques
}

\author{
Michelle Kavin · Raquel M. Añel-Tiangco · David T. Mauger · Robert A. Gabbay
}

Received: October 19, 2010 / Published online: January 11, 2011

(C) The Author(s) 2010. This article is published with open access at Springerlink.com

\section{ABSTRACT}

Introduction: The primary objective of this work was to develop a diabetes education book, to pilot its use, and to evaluate its impact on patient care. The secondary objective was to compare the value of providing only the book to patients versus providing the book along with a brief tutorial given by a nurse on how to use the book. Methods: A diabetes education book was developed through a social marketing approach. The impact of the book was then tested in a pilot, prospective, randomized controlled trial evaluating diabetes knowledge, emotional distress, self-care behavior, and clinical outcomes in a primary care patient population. The three-arm study randomized one group to usual care $(n=33)$, one group to

Michelle Kavin • Raquel M. Añel-Tiangco •

Robert A. Gabbay $(\triangle)$

Penn State Institute for Diabetes and Obesity and Division of Endocrinology, Diabetes and Metabolism, 500 University Drive, H044, Hershey, Pennsylvania 17033, USA. Email: rgabbay@psu.edu

David T. Mauger

Department of Public Health Sciences, Penn State College of Medicine, Hershey, Pennsylvania, USA receive the book alone ( $n=33)$, and one group to receive the book with a brief nurse tutorial $(n=34)$. Patients completed surveys at baseline, 4 weeks, 3 months, and 6 months to assess knowledge (Knowledge Questionnaire), selfcare behaviors (Summary of Diabetes Self Care Activities [SDSCA] survey), and diseaserelated distress (Problem Areas in Diabetes [PAID] scale). Results: A patient advocacy committee identified a need for information on basic diabetes knowledge, diet, medications, complications, preparing for a visit, and plans for daily life. Using social marketing with a focus on low literacy, the Penn State Hershey Diabetes Playbook was created. The pilot study showed a trend towards improved knowledge, decreased distress, and improved self-care behaviors in patients who received the book. There was no difference in outcomes in patients who were provided the book alone versus those who received a brief nurse tutorial along with the book. Conclusion: Social marketing techniques and low literacy awareness are useful in developing diabetes educational materials.

Keywords: diabetes Playbook; low literacy; patient empowerment; self-education; social marketing 


\section{INTRODUCTION}

Two out of three Americans still fail to meet widely acknowledged treatment goals shown to reduce complications and costs from diabetes, as set forth by ground-breaking studies released nearly a decade ago. ${ }^{1-3}$ In order to reach these treatment goals, patients need to adhere to a healthy diet, obtain regular exercise, use medications appropriately, be consistent with glucose monitoring, and possess the ability to make daily management decisions. ${ }^{4}$ These daily self-care behaviors, along with disease awareness and self-management skills, have proven critical to good diabetes outcomes. ${ }^{5-9}$ However, the current medical care system, with limited practitioner time, inadequate patient educational materials, and lack of self-management training, has proven poor at teaching these skills. Additionally, while diabetes education has shifted from the primarily didactic intervention of the 1970s and 1980s into the collaborative, "self-empowerment" models of the 1990s, written patient resources generally have failed to evolve with this transformation. ${ }^{10}$

Research has shown that materials developed by members of the target audience reflect their voices and concerns far better than industryproduced equivalents. ${ }^{11}$ In recent years, various government and nonprofit organizations have used social marketing to influence a wide variety of health behaviors such as increasing fruit and vegetable consumption, decreasing fat intake, promoting breastfeeding, and promoting physical activity. ${ }^{12}$ However, little research has been undertaken on written diabetes educational materials developed in this manner.

One of the strategies to involve patients in their own healthcare is social marketing. Social marketing uses commercial marketing techniques to develop programs and educational materials aimed at changing behavior. It is based on the premise that effective change starts with a thorough understanding of the wants and needs of patients. ${ }^{13}$ This differs from more traditional, expert-driven approaches in which public health professionals develop healthcare programs without getting patients involved in the process.

Social marketing engages members of the population of interest to create tools that best fit their needs. It facilitates the acceptance, rejection, modification, abandonment, or maintenance of particular behaviors. ${ }^{14}$ What makes social marketing unique is that patients are involved at all stages of the program development. This is different from traditional approaches where healthcare professionals decide what patients need to know or do. By allowing the patients to make decisions, the final product will reflect their point of view and promote their success.

The social marketing process begins with planning and strategizing. Then, channels through which to target the patients must be chosen. Material is then developed and assessed using the patients' input. The program is then redesigned based on their responses. After initial completion, the program is implemented and reassessed. It can then be refined as needed to fit the needs of the patients.

Another problem with the current written patient educational materials is that they often fail to take into consideration the patients' literacy levels. As noted in the Clear Health Communication Initiative, millions of patients encounter difficulties when they try to understand health information. Inadequate health literacy in patients with diabetes, in particular, is linked to worse glycemic control and fewer self-management behaviors. ${ }^{15,16}$ The National Adult Literacy Survey (NALS) in 1992 interviewed 24,944 adults and estimated that around $50 \%$ of the adult population has limited reading and quantitative skills. ${ }^{17}$ 
One out of five American adults reads at the fifth grade level or below and the average American reads at the eighth to ninth grade level. Yet most healthcare materials are written above the 10th grade level. ${ }^{17}$ Ophthalmic, ${ }^{18}$ cholesterol, ${ }^{19}$ and diabetes educational materials ${ }^{20}$ were analyzed and scored at reading levels well above the ninth grade level. While studies have been used to develop research tools to test health literacy, ${ }^{17,}$ 21-23 literature from the health field provides limited information on research-based strategies to meet the needs of those with low levels of health literacy. ${ }^{24}$ Common sense dictates that those struggling with health literacy issues would have less difficulty with materials that are written at lower reading levels. However, this strategy by itself may fall short of addressing the needs of those with low health literacy skills and instead tends to benefit most those with higher skill levels who report that they prefer such materials. ${ }^{25}$ Other studies highlight the importance of layouts, typeface, style, size, white space, primacy of key information, and the use of active versus passive voice. ${ }^{26-33} \mathrm{With}$ these in mind, a low literacy design was used in the development of the current written educational material.

\section{METHODS}

The process began by meeting with patient advocacy groups and focus groups ranging from 4-40 people on about 10 different occasions to determine their concerns. The groups were comprised of patients who learned about the study from their providers, health fairs, and advertisements distributed to patients in our Diabetes Registry. They identified lack of concise, motivating, and easy-to-read material as a major concern. Patients felt that multiple handouts given to them were not easy to understand and were often misplaced and lost. They envisioned a binder that would hold the information they had learned about diabetes and self-management. Critical needs included basic information about diabetes, food and medication choices, how to address daily life concerns and prepare for office visits, and how to stay organized. Interestingly, they did not put as much importance on understanding the pathology of the disease, learning how to interpret laboratory values, and reviewing the need for exercise. In their opinion, these topics were not as important to them as they were to the medical staff.

A basic book was then developed in a binder format and presented to more patient focus groups for review. The group had input on content, reading level, layout, typeface, style, primacy of key information, themes, and overall appearance. To ensure health literacy, our book addresses all of these areas and adheres to a Flesch-Kincaid Reading Ease formula ${ }^{34}$ to produce fifth to sixth grade reading level material based on word, sentence, and paragraph lengths. The patients also added ideas such as placing pockets to store medical office business/appointment cards, incorporating pictures and quotes from staff and patients to make it inspirational, and changing food choices in the dietary section to better reflect cultural diversity. They also recommended the addition of contact information for local medical clinics, diabetes education programs, and national diabetes organizations that offered information and support. Several charts to improve self-management and organizational skills were developed. These included tracking prescriptions/refills, logging food choices, and listing medical appointment dates. Patients authored sections of the book, particularly those related to emotional aspects of diabetes. All written material was again reviewed to ensure low literacy compliance. 
Development and evaluation was continued in this manner. Overall, 1 year was spent working with a patient advocacy group, patient authors, and patient focus groups. Using a social marketing approach, their input was used to create the Penn State Hershey Diabetes Playbook, which was published in October 2006. ${ }^{35}$

\section{Pilot Study Design}

A prospective, randomized controlled pilot study was conducted to evaluate the effectiveness of the Penn State Hershey Diabetes Playbook in improving diabetes knowledge, emotional distress, self-care behavior, and clinical outcomes in a primary care patient population. The threearm study had one group adhering to usual care, one group receiving the Playbook, and one group receiving the Playbook along with a nurse tutorial on it. Two nurses specifically trained in diabetes care and behavior-change techniques were used for the last arm. They spent 15-30 minutes reviewing the book with each patient and helping them understand how they can use it to meet their needs.

Patients were recruited from January to August 2008. Inclusion criteria were patients 18-75 years old (75 was chosen as the cut-off point in order to obtain a more homogenous population for the study); diagnosed type 2 diabetes; patient of the Internal Medicine clinic; and English speaking. Exclusion criteria were patients < 18 years old; >75 years old; nonEnglish speaking; living in a nursing home; and unable to change dietary choices. Patients were assessed for eligibility using a patient registry at a university-based Internal Medicine clinic.

All patients provided written informed consent before entering the study. Of those assessed, 100 patients were randomized using a computer-generated scheme. All patients were asked to complete three validated surveys
(Problem Areas in Diabetes [PAID], Summary of Diabetes Self Care Activities [SDSCA], Knowledge; see below, for descriptions) at baseline, 4 weeks, 3 months and 6 months. Glycated hemoglobin $\left(\mathrm{HbA}_{1 \mathrm{c}}\right)$ levels were ascertained at baseline, 3 months, and 6 months.

1. The PAID scale assesses emotional distress (20 items). This survey has been found to be highly reliable and responsive to changes during brief psychosocial and educational interventions. ${ }^{36}$

2. The SDSCA survey (25 items) is used to evaluate individuals' self-care behavior and adherence to diet, exercise, blood glucose testing, foot care, smoking, and selfcare recommendations. ${ }^{37}$

3. The Knowledge Questionnaire (20 items) was designed for this study to assess general disease knowledge, carbohydrate understanding, and treatment of hypoglycemia and was based on the Michigan Knowledge Test. ${ }^{38}$

\section{Analysis}

Descriptive statistics, including the mean, median, standard deviation, and quartiles, were calculated for baseline measurements of continuous variables while frequency tables were constructed for categorical variables. Repeated measured analysis of variance was used to model the group means across time for continuous variables including $\mathrm{HbA}_{1 \mathrm{c}}$, total Knowledge score, total PAID score, and PAID subscores. Linear contrasts were used to compare the groups across time. Since $\mathrm{HbA}_{1 \mathrm{c}}$ measurements were not necessarily taken at study visits, $\mathrm{HbA}_{1 \mathrm{c}}$ values for analysis were extracted from the clinical database and were selected to coincide, within \pm 2 months, with the dates of the baseline and 6-month study follow-up visits. Repeated measured analysis 
variance models were implemented using PROC MIXED in SAS version 9.1 (SAS Inc., Cary, NC, USA).

Power calculations for this study design indicate that a total sample size of 35 per group would have $80 \%$ power to detect a relative effect size of 0.75 for the comparison of each experimental group against the control group. This equates to an absolute effect size of approximately 1.7 for the total Knowledge score, 1.6 for the General Diet score, 0.9 for the Exercise score, 19 for the PAID score, and 1.5 for $\mathrm{HbA}_{1 \mathrm{c}}$.

\section{RESULTS}

The study resulted in the creation of the Penn State Hershey Diabetes Playbook, a 70-page,

Figure 1. Sample page from the Penn State Hershey Diabetes Playbook. The Playbook is divided into seven sections: Diabetes 101, Food, Medication, Wellness, Daily Life, Visits, and Resources.

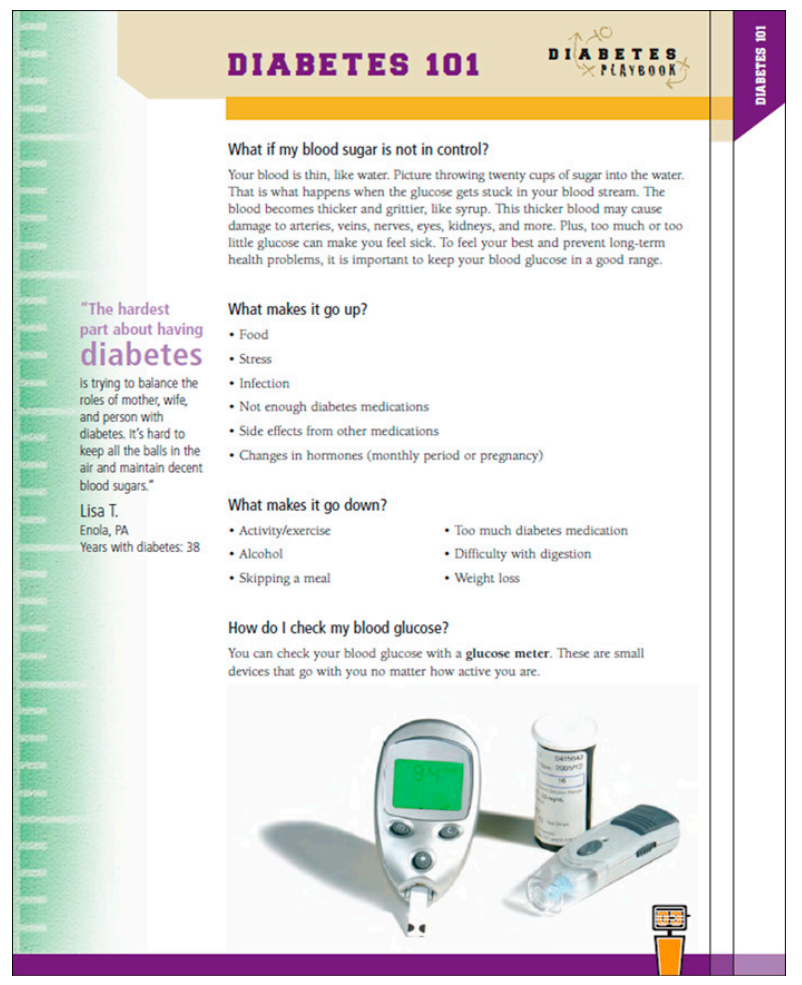

seven-section, three-ring-binder package full of information and action plans to help patients better understand and manage their diabetes (see Figure 1 for a sample page). It received the 2008 American Association of Diabetes Educators Allene Van Son award for best-written patient education material of the year. It also received recognition in the marketing industry as a gold winner in the 24th Annual Healthcare Marketing Advertising Report Awards, recognized for its effective way of delivering its diabetes education message. There are now more than 5000 copies in print and development is ongoing for a Spanish version and an electronicformat version. ${ }^{35}$ The Playbook is considered a great success by patients and staff. A PDF copy can be downloaded from the Penn State Hershey Medical Center's web site. ${ }^{35}$

The pilot study was designed to assess its ability to improve knowledge, bolster self-care behaviors, decrease emotional distress, and improve clinical outcomes in a primary care setting. A total of 65 patients completed the project with 35 lost to follow-up or withdrawn (Figure 2). Over 80\% were Caucasian, 12\% were black, and the remainder were Hispanic or Asian. The patients had diabetes for an average of 9 years. One-third of the patients were high school graduates or had received their General Educational Development (GED) equivalent. About half of the participants had an education limited to high school.

Analysis of the results showed a trend towards improved knowledge, decreased distress, and improved self-care behaviors (adherence to diet and exercise) in patients who received the book. Although there was no difference between the group who received the book alone compared with the group who received a brief nurse tutorial along with the book, the book by itself appeared to have an impact. Comparing the change over 6 months, 
Figure 2. Enrollment and outcomes Consolidated Standards of Reporting Trials (CONSORT) diagram. Of the 1020 patients assessed for eligibility, 100 were randomized. Overall, $65 \%$ completed the study and $35 \%$ were lost to followup or withdrawn.

\section{Enrollment}

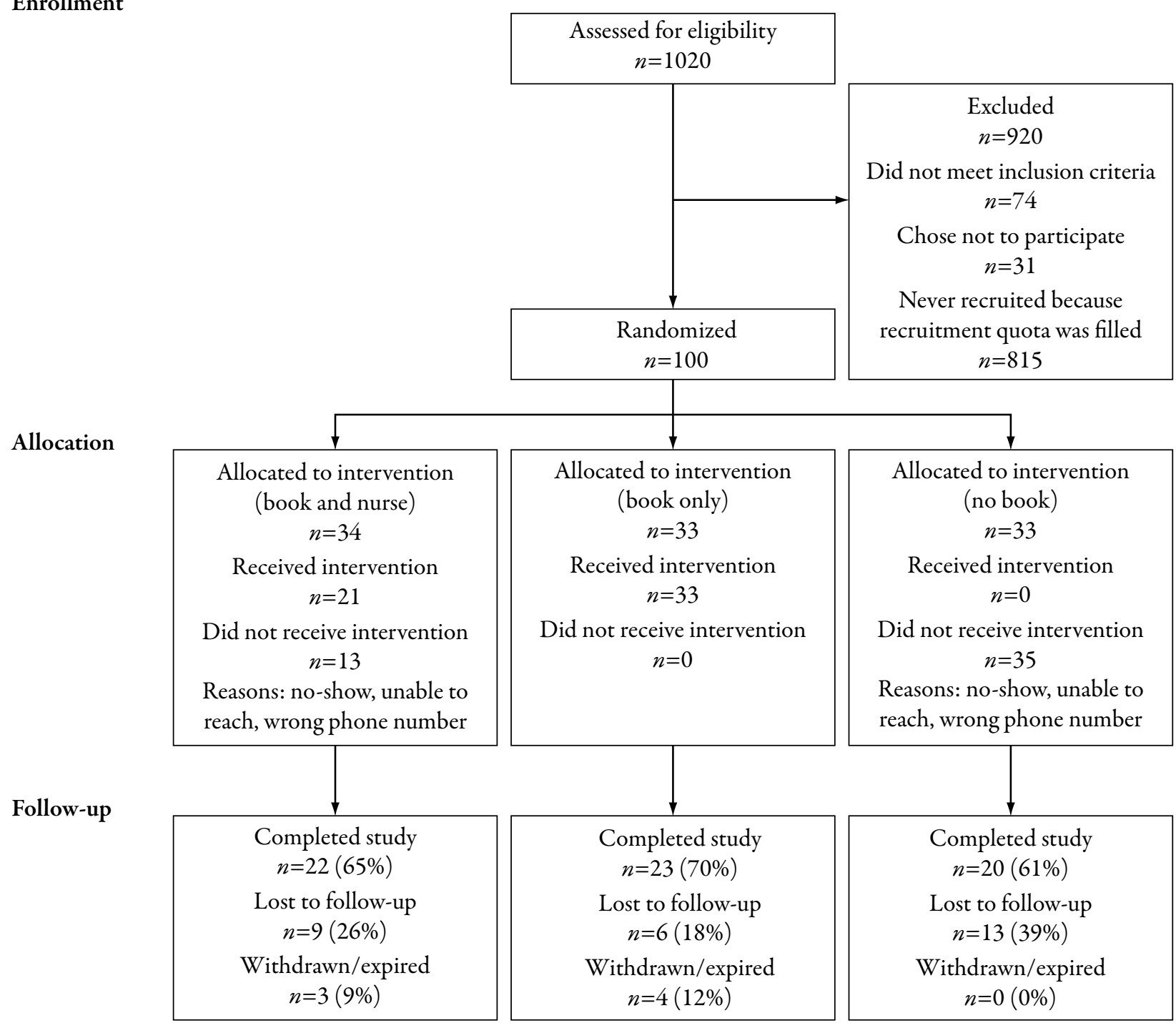

PAID scores were improved in those patients who received the book compared with those who did not ( -4.33 vs. $-4.19, P=0.97)$. Similar improvements in General Diet scores (1.26 vs. -0.24, $P=0.034)$ and Exercise scores (0.5 vs. $-0.85, P=0.010)$ were observed. The lack of an impact of the brief nurse tutorial is likely due to the fact that $50 \%$ of patients scheduled to see the nurse for the tutorial did not keep their appointment. There was a clear difference in the patients who complied with seeing a nurse. Those who saw the nurse had an average $\mathrm{HbA}_{1 \mathrm{c}}$ of $6.8 \%$ compared with those who did not keep their appointment who had an average $\mathrm{HbA}_{1 \mathrm{c}}$ of $8.05 \%$. At the end of the 6-month project, changes in $\mathrm{HbA}_{1 \mathrm{c}}$ between the intervention group and the control group did not reach statistical significance (Figure 3). 
Figure 3. Pilot study results. (A) Trends in glycated hemoglobin $\left(\mathrm{HbA}_{1 \mathrm{c}}\right)$ levels. (B) Emotional Distress (Problem Areas in Diabetes [PAID] scale) scores. (C) Knowledge Questionnaire scores. (D) and (E) show the General Diet and Exercise Adherence subscores for the Summary of Diabetes Self Care Activities (SDSCA) survey.
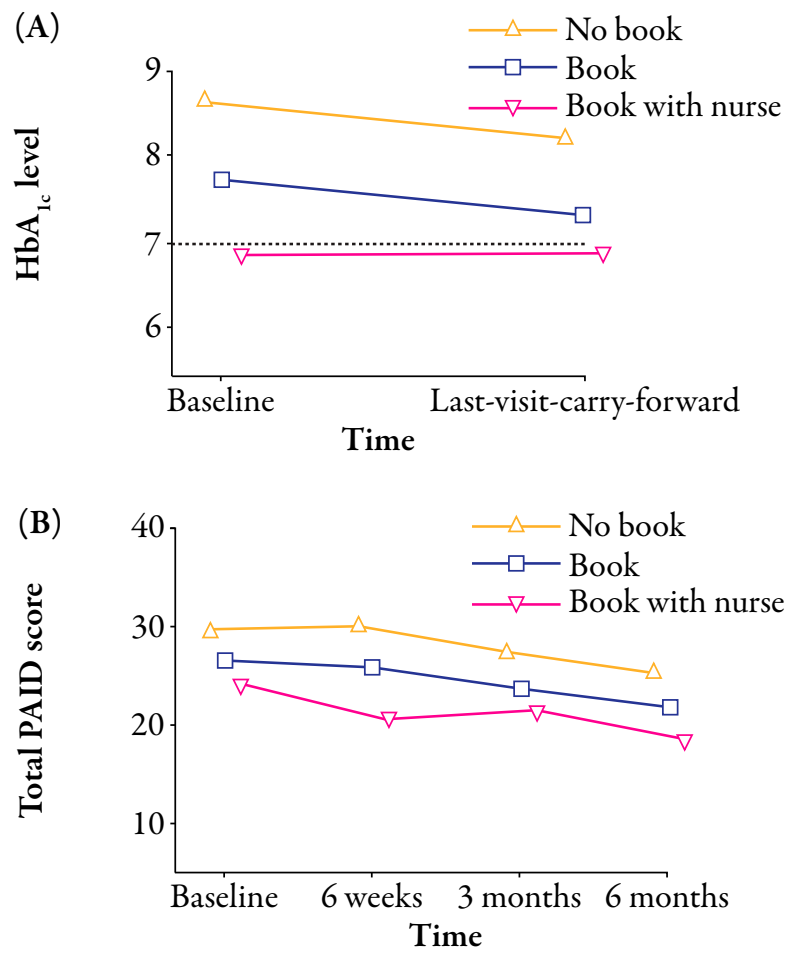

\section{DISCUSSION}

Disease awareness, self-management skills, and self-care behaviors are critical to maintaining glucose control and improving outcomes in diabetes care. While diabetes education has shifted from the primarily didactic intervention of the 1970s and 1980s into the collaborative, "self-empowerment" models of the 1990s, patient handouts have failed to evolve with it. ${ }^{10}$ This project was one of the few devoted to using social marketing to create a low-
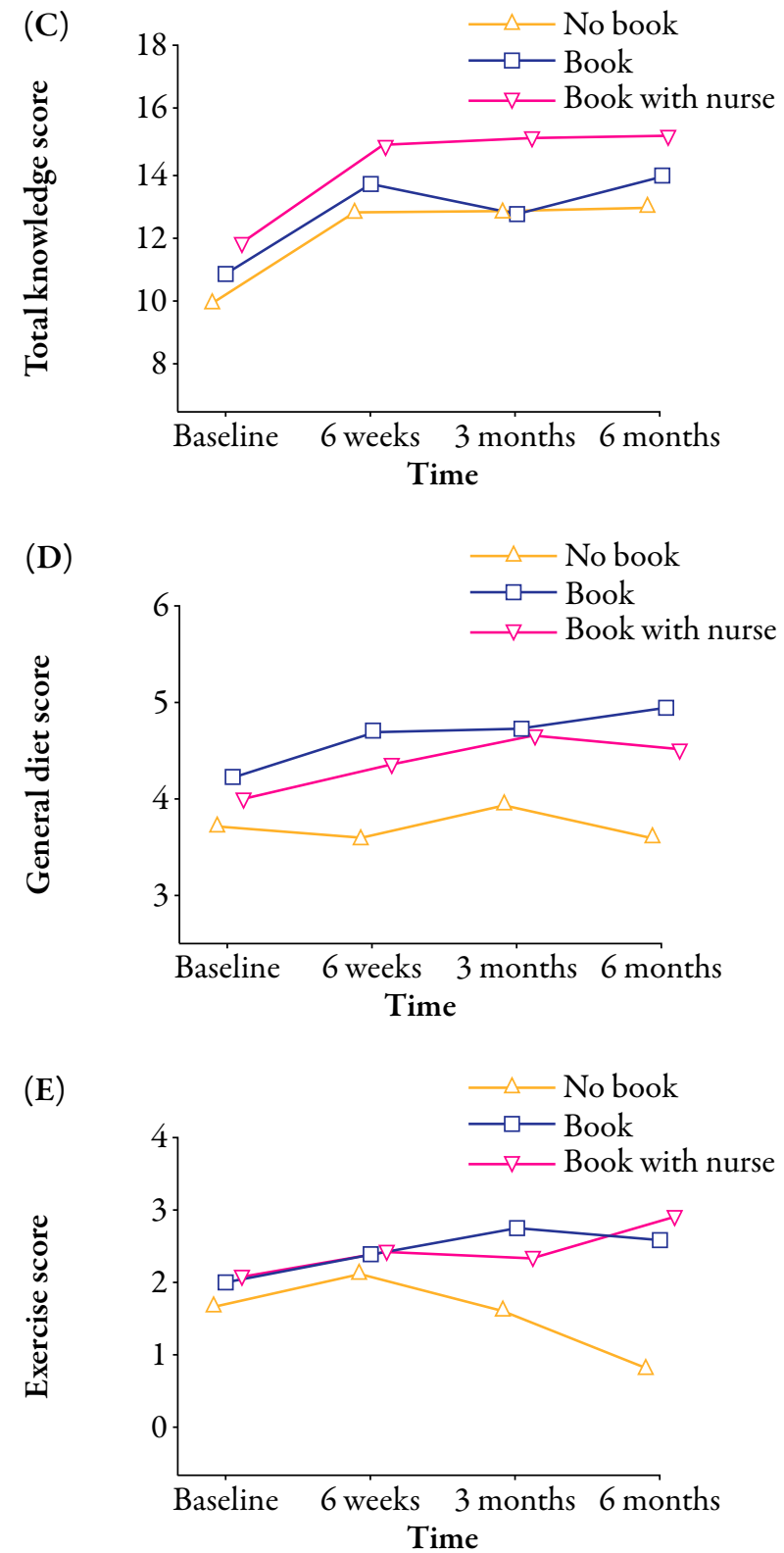

literacy written patient educational material for the treatment of diabetes. Both patients and medical professionals were highly engaged and found great satisfaction in making the book, indicating that social marketing and low literacy techniques are effective ways to develop educational tools.

Some key lessons learned during the development of the book were the importance of: (1) breaking down key points in bullets to 
give patients specific action items, (2) focusing on actionable information and minimizing detailed pathophysiology, (3) providing detailed information on diet and food (the most common request from the patients during focus groups), and (4) including a section on emotional aspects.

This study provided a 6-month pilot evaluation of the ability of a patient-driven book used with or without a nurse tutorial to change patients' knowledge of their disease state, selfcare behaviors, emotional distress, and clinical outcomes. The results showed a trend towards increased knowledge, decreased distress, and improved self-care behaviors.

Clinical outcomes were not affected by the interventions, however. These results are consistent with current literature showing greater patient knowledge alone does not correlate with improved glycemic control. Simply providing information more clearly is not enough to motivate patients. ${ }^{39}$ However, a minimum threshold of diabetes knowledge is required to promote better outcomes.

One limitation of the study was that the impact of the book was studied on patients who had diabetes for an average of 10 years even though the intended target population of the book is adult patients with new-onset diabetes. Patients who have had diabetes longer may have already achieved a baseline of emotional acceptance, general knowledge, and established self-care behaviors above those who are newly diagnosed. Enrolling only patients who were newly diagnosed may have provided a greater effect.

Another limitation was that an initial assessment of health literacy in the study patient population was not obtained. The Flesch-Kincaid Reading Ease formula ${ }^{34}$ was used to produce fifth to sixth grade reading level material based on word, sentence, and paragraph lengths. However, it is not known if this was an appropriate level for our patient population.

There may also have been a Hawthorne effect whereby patients observed during a research study temporarily change their behavior or performance because they are part of the study despite what intervention is used. It was noted that all groups had a statistically significant increase in knowledge regardless of which arm they were assigned.

Additional research on the use of social marketing to improve patient educational materials is needed. Research may help decipher the needs of patients at different stages of disease acceptance and awareness. It can assess different material types such as written and interactive computer-based programs. Working with groups of different ethnicities and geographic locations will also help develop materials suited to populations that may be different from ours.

\section{CONCLUSION}

Social marketing techniques and low literacy awareness are useful in developing diabetes educational materials. These strategies promote the patients' capacity to define the problems they are facing, make informed decisions about their management, and set realistic targets and strategies to meet those goals.

\section{ACKNOWLEDGMENTS}

We would like to thank Susan Rathfon-Coble, Scott Mincemoyer, and Bernie Banas for their assistance. RAG is the guarantor for this article, and takes responsibility for the integrity of the work as a whole.

Open Access. This article is distributed under the terms of the Creative Commons Attribution Noncommercial License which 
permits any noncommercial use, distribution, and reproduction in any medium, provided the original author(s) and source are credited.

\section{REFERENCES}

1. UK Prospective Diabetes Study (UKPDS) Group. Intensive blood-glucose control with sulphonylureas or insulin compared with conventional treatment and risk of complications in patients with type 2 diabetes (UKPDS 33). Lancet. 1998;352:837-853.

2. The Diabetes Control and Complications Trial Research Group. The effect of intensive treatment of diabetes on the development and progression of long-term complications in insulin-dependent diabetes mellitus. N Engl J Med. 1993;329:977-986.

3. American Association of Clinical Endocrinologists. State of diabetes in America. Available at: www. aace.com/public/awareness/stateofdiabetes/ DiabetesAmericaReport.pdf. Accessed March 1, 2010.

4. Martins RK, McNeil DW. Review of motivational interviewing in promoting health behaviors. Clin Psychol Rev. 2009;29:283-293.

5. Anderson R, Funnel M, Carlson A, Saleh-Statin $\mathrm{N}$, Cradock S, Skinner TC. Facilitating self-care through empowerment. In: Snoek FJ, Skinner TS, eds. Psychology in Diabetes Care. Chichester: John Wiley \& Sons; 2000:69-97.

6. Rubin RR. Psychotherapy and counseling in diabetes mellitus. In: Snoek FJ, Skinner TS, eds. Psychology in Diabetes Care. Chichester: John Wiley \& Sons; 2000:235-263.

7. Robiner W, Kell PK. Self-care behaviors and adherence in diabetes mellitus. Semin Clin Neuropsychiatry. 1992;2:40-56.

8. Ruggiero L, Glasgow R, Dryfoos JM, et al. Diabetes self-management. Self-reported recommendations and patterns in a large population. Diabetes Care. 1997;20:568-576.

9. Glasgow RE, Eakin EG. Medical office-based interventions. In: Snoek FJ, Skinner TS, eds. Psychology in Diabetes Care. Chichester: John Wiley \& Sons; 2000:141-168.

10. Norris SL, Engelgau MM, Narayan KM. Effectiveness of self-management training in type 2 diabetes: a systematic review of randomized controlled trials. Diabetes Care. Mar 2001;24:561-587.

11. Rudd RE, Comings JP. Learner developed materials: an empowering product. Health Educ Q. 1994;21:313-327.

12. Coreil J, Bryant CA, Henderson JN. Social and Behavioral Foundations of Public Health. Thousand Oaks, CA: Sage; 2000.

13. Andreasen AR. Marketing Social Change: Changing Behavior to Promote Health, Social Development and the Environment. San Francisco, CA: JosseyBass; 1995.

14. Kotler P, Roberto N, Lee N. Social Marketing: Improving the Quality of Life. Thousand Oaks, CA: Sage; 2002.

15. Schillinger D, Grumbach $\mathrm{K}$, Piette J, et al. Association of health literacy with diabetes outcomes. JAMA. 2002;288:475-482.

16. Cavanaugh $\mathrm{K}$, Huizinga MM, Wallston KA, et al. Association of numeracy and diabetes control. Ann Intern Med. 2008;148:737-746.

17. Kirsch IS, Jungeblut A, Jenkins L, Kolstad A. Adult Literacy in America: a First Look at the Results of the National Adult Literarcy Survey. Washington, DC: US Department of Education; 1993.

18. Ebrahimzadeh H, Davalos R, Lee PP. Literacy levels of ophthalmic patient education materials. Surv Ophthalmol. 1997;42:152-156.

19. Glanz K, Rudd J. Readability and content analysis of print cholesterol education materials. Patient Educ Couns. 1990;16:109-118.

20. Leichter SB, Nieman JA, Moore RW, Collins P, Rhodes A. Readability of self-care instructional pamphlets for diabetic patients. Diabetes Care. 1981;4:627-630.

21. Davis TC, Long SW, Jackson RH, et al. Rapid estimate of adult literacy in medicine: a shortened screening instrument. Fam Med. 1993;25:391-395.

22. Parker RM, Baker DW, Williams MV, Nurss JR. The test of functional health literacy in adults: a new instrument for measuring patients' literacy skills. J Gen Intern Med. 1995;10:537-541.

23. Cavanaugh K, Wallston KA, Gebretsadik T, et al. Addressing literacy and numeracy to improve diabetes care: two randomized controlled trials. Diabetes Care. 2009;32:2149-2155. 
24. Rudd RE, Moeykens B, Colton T. Health and Literacy: A Review of Medical and Public Health Literature. New York, NY: Jossey-Bass; 1999.

25. Plimpton S, Root J. Materials and strategies that work in low literacy health communication. Public Health Rep. 1994;109:86-92.

26. US Department of Agriculture. Guidelines: Writing for Adults with Limited Reading Skills. Washington, DC: US Government Printing Office; 1988.

27. US Department of Health and Human Services. Making Health Communication Programs Work: a Planner's Guide (NIH Publication No. 89-1493). Washington, DC: NIH Office of Cancer Communications; 1989.

28. Doak CC, Doak LG, Friedell GH, Meade CD. Improving comprehension for cancer patients with low literacy skills: strategies for clinicians. CA Cancer J Clin. 1998;48:151-162.

29. Murphy PW, Davis TC, Jackson RH, Decker BC, Long SW. Effects of literacy on health care of the aged: implications for health professionals. Educ Gerontol. 1993;19:311-316.

30. Forster J, Davis TC, Meldrum H, Tippy PHP, Weiss BD, Williams M. How poor literacy leads to poor health. Patient Care. 1996;15:94-127.

31. Mayeaux EJ, Jr., Murphy PW, Arnold C, Davis TC, Jackson RH, Sentell T. Improving patient education for patients with low literacy skills. Am Fam Physician. 1996;53:205-211.
32. Szudy E, Arroyo MG. The Right to Understand: Linking Literacy to Health and Safety Training. Berkley, CA: Labor Occupational Health Program, Publications, University of California, Berkley; 1994.

33. Doak CC, Doak LG, Root JH. Teaching Patients with Low Literacy Skills. 2nd edition. Philadelphia, PA: JB Lippincott; 1996.

34. Flesch R. A new readability yardstick. J Appl Psychol. 1948;32:221-233.

35. Penn State Hershey Diabetes and Obesity Institute. Diabetes Playbook. Available at: http:// pennstatehershey.org/web/diabetesandobesity/ patientcare/patientresources/diabetesplaybook. Accessed March 1, 2010.

36. Welch GW, Jacobson AM, Polonsky WH. The Problem Areas in Diabetes Scale. An evaluation of its clinical utility. Diabetes Care. 1997;20:760-766.

37. Toobert DJ, Hampson SE, Glasgow RE. The summary of diabetes self-care activities measure: results from 7 studies and a revised scale. Diabetes Care. 2000;23:943-950.

38. Fitzgerald JT, Funnell MM, Hess GE, et al. The reliability and validity of a brief diabetes knowledge test. Diabetes Care. 1998;21:706-710.

39. Heisler M, Piette JD, Spencer M, Kieffer E, Vijan S. The relationship between knowledge of recent HbA1c values and diabetes care understanding and self-management. Diabetes Care. 2005;28:816-822. 